Research Article

\title{
Relationship between the Molecular Coil Dimension and the Energy Storage Modulus of Polymer Solution Configured with Oilfield-Produced Sewage
}

\author{
Peng Wang, ${ }^{1,2,3}$ Wenguo Ma ${ }^{\mathbb{D}},{ }^{4}$ Yunbao Zhang, ${ }^{5}$ and Qiuyan Yan ${ }^{6}$ \\ ${ }^{1}$ Guangzhou Institute of Geochemistry, Chinese Academy of Science, Guangzhou 510640, China \\ ${ }^{2}$ University of Chinese Academy of Science, Beijing 100049, China \\ ${ }^{3}$ Sixth Oil Production Factory, Daqing Oil Field, PetroChina, Daqing 163318, China \\ ${ }^{4}$ Key Laboratory of Enhancing Oil and Gas Recovery of Education Ministry, School of Petroleum Engineering, \\ Northeast Petroleum University, Daqing 163318, China \\ ${ }^{5}$ Bohai Oil Research Institute, Tianjin Branch of CNOOC Ltd., Tianjin 300450, China \\ ${ }^{6}$ Institute of Chemical Engineering, Northeast Petroleum University, Daqing 163318, China
}

Correspondence should be addressed to Wenguo Ma; mawenguo110@163.com

Received 28 September 2019; Revised 22 May 2020; Accepted 3 June 2020; Published 22 June 2020

Academic Editor: Valentina Venuti

Copyright (c) 2020 Peng Wang et al. This is an open access article distributed under the Creative Commons Attribution License, which permits unrestricted use, distribution, and reproduction in any medium, provided the original work is properly cited.

\begin{abstract}
Polymer viscoelastic solution is the non-Newtonian fluid and widely used in oil production. In the process of seepage, the mechanism of the polymer solution with different molecular coil dimensions (Dh) flooding on remaining oil is unknown. By using the dynamic light scattering instrument, the molecular coil dimension of the polymer solution is tested. By using the HAAKE rheometer, the creep recovery test data of the polymer solution under the same creep time condition are obtained. The effects of polymer solutions with different $\mathrm{Dh}$ on residual oil are observed, by using the visible pore model. The results show that the higher the molecular weight $\left(M_{\mathrm{w}}\right)$ of the polymer, the larger the size of the molecular coil dimension. The elasticity characteristics of the polymer solution are sensitive to the molecular coil dimension. As Dh of polymer molecules becomes larger, the contribution of the elastic portion to the viscosity of the polymer solution increases. The higher the $M_{\mathrm{w}}$ of polymer is, the longer the molecular chain is and the size of $\mathrm{Dh}$ is larger. On the condition of the polymer solution with different $M_{\mathrm{w}}$ with $2.5 \mathrm{~g} / \mathrm{L}$, when $\mathrm{Dh}$ is between $320.0 \mathrm{~nm}$ and $327.8 \mathrm{~nm}$, the ratio of the elastic part in the apparent viscosity exceeds the proportion of the viscous part, and the polymer solution composition after these data can be used as a comparative study of elasticity for residual oil use. In the visible pore model, the pore-throat ratio is 3.5 , the $E_{\mathrm{R}}$ of water flooding is $54.26 \%$, the $E_{\mathrm{R}}$ of the polymer solution with $\mathrm{Dh}=159.7 \mathrm{~nm}$ is $75.28 \%$, and the increase of $E_{\mathrm{R}}$ is $21.02 \%$ than that of water flooding. With the increase of $\mathrm{Dh}$ to $327.8 \mathrm{~nm}$, the final $E_{\mathrm{R}}$ of the experimental polymer solution is $97.82 \%$, and the increase of $E_{\mathrm{R}}$ of the polymer solution than that of water flooding is $43.56 \%$. However, in the model with a pore-throat ratio of 7.0 and the same polymer solution with $\mathrm{Dh}=327.8 \mathrm{~nm}$, the increase of $E_{\mathrm{R}}$ of the polymer solution is only $10.44 \%$ higher than that of water flooding. The effect of the polymer solution with the same $\mathrm{Dh}$ is deteriorated with the increase of the porethroat ratio.
\end{abstract}

\section{Introduction}

With the gradual expansion of the application scale of polymer flooding and composite system, the water resources used for the preparation of the polymer solution are becoming increasingly tense; at the same time, a large number of produced water bring great pressure on environmental protection [1-4]. The viscoelastic properties of the polymer solution are the key factors affecting oil recovery and the type of residual oil [5-9]; the test results of the 
geometrical form of the polymer molecules in the polymer system configured with the treated sewage directly affect the polymer system and the pore adaptability, thereby affecting the microscopic residual oil use effect [10-14]. In this paper, the use of oilfield-produced sewage to prepare the polymer solution has become an inevitable choice for the oilfield production. By using the dynamic light scattering instrument, the viscosity, elasticity, and the molecular coil dimension (Dh) are studied. As an effective parameter, the creep recovery test can be used to study the viscoelasticity of the polymer solution. The relationship between molecular storage modulus of the polymers (prepared by the oilfieldproduced water) is analyzed, and both the $M_{\mathrm{w}}$ and the concentration of polymer $\left(C_{\mathrm{p}}\right)$, combined with the core model designed by the pore structure of the actual reservoir, guide the hydrolysis of the indoor oil flooding experiment, and the changes of micro remaining oil in sandstone of pore size level is studied, and the best polymer system for oil displacement suitable for experimental pore construction parameter data is given.

\section{Test Instruments for Molecular Coil Dimension and Creep Recovery}

2.1. Test Instruments. The instrument used is a wide angle dynamic/static light scattering system type BI-200SM (Brookhaven Instruments Corp, USA), as shown in Figure 1; the main components of the system include a laser correlator (Type BI-9000AT), signal processing apparatus, and argon ion laser (power: $200 \mathrm{~mW}$ and wave length: $532.0 \mathrm{~nm}$ ). The dynamic light scattering instrument used in this research can directly test Dh. Dh can be used to characterize the crimping degree of polymer chains and molecular coil dimension.

The instrument HAAKE RS150 rheometer (Germany) used in this test for creep recovery is shown in Figure 2. The constant temperature is the water temperature $s$ at $45^{\circ} \mathrm{C}$ in this test, and data are automatically controlled by a computer. The C60/1Ti cone plate is adopted in the test (Taper: $\left.1^{\circ}\right)$, the shear rate itables $0.1 \sim 1000(1 / \mathrm{s})$, and the cone gap of the test system is $0.052 \mathrm{~mm}$.

2.2. Creep Recovery Test Principle. In the creep recovery experiment, as shown in Figure 3, during the creep period (time from $0 \mathrm{~s}$ to $60 \mathrm{~s}$ ), with a constant stress (stress $=0.005 \mathrm{~Pa}$ ) applied, the straining increases with time. The stress is removed after $60 \mathrm{~s}$; until $360 \mathrm{~s}$ is the recovery period, the straining decreases sharply first and then reach a stable value. The stable straining $\left(\gamma_{\mathrm{ss}}\right)$ is the contribution of the viscosity parts of the polymer solution, and the recoverable straining $\left(\gamma_{\max }-\gamma_{\mathrm{ss}}\right)$ is the contribution of the elasticity parts. The percentage of total straining $\left(\gamma_{\max }\right)$ can be decomposed into viscosity parts and elasticity parts. The proportion of the straining contributed by elasticity parts $\left(E_{\mathrm{e}}\right)$ and the strain contributed by viscosity parts $\left(E_{\mathrm{v}}\right)$ to the total straining reflect the elasticity and viscosity of the viscoelastic polymer solution; the calculation formula is shown in the following formula:

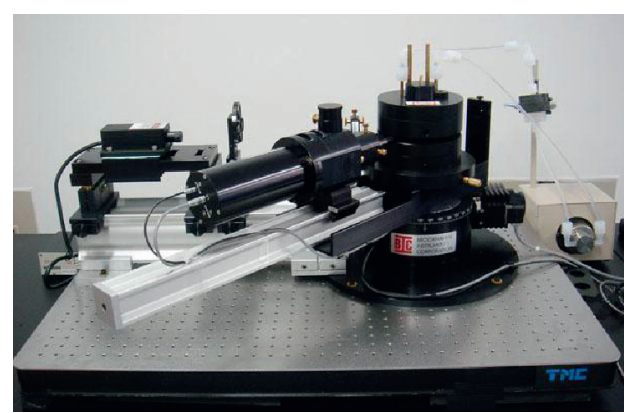

FIgUre 1: BI-200SM wide angle dynamic/static light scattering system.

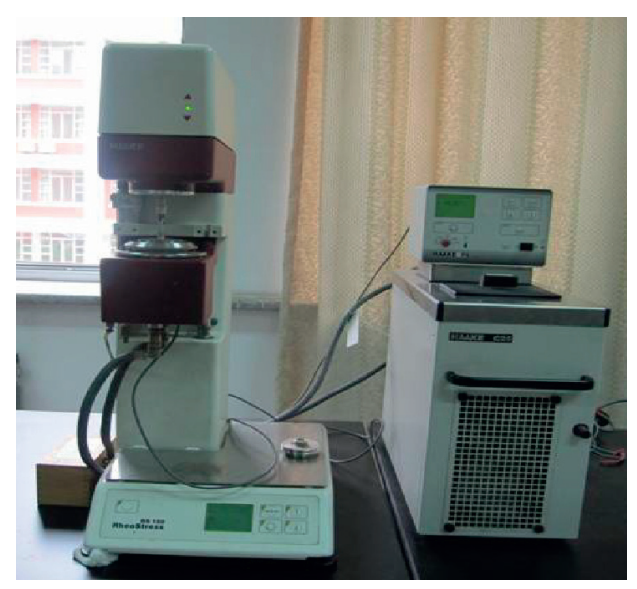

Figure 2: HAAKE RS150 rheometer.

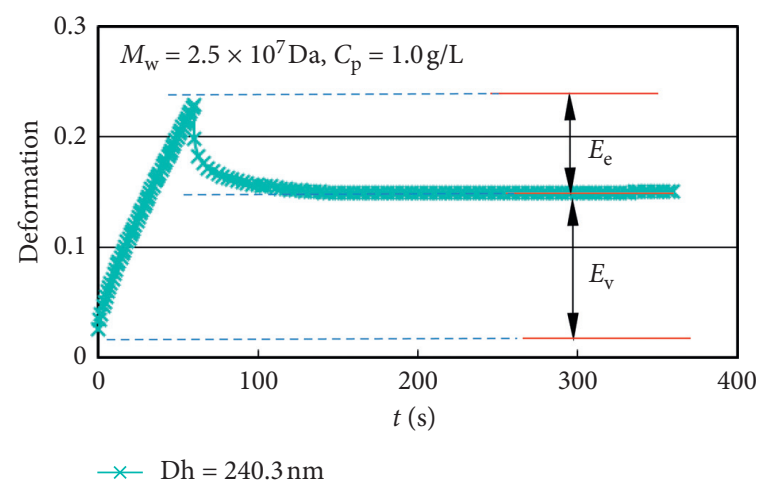

Figure 3: Creep recovery curves of the polymer solution with different Dh $(0.5 \mathrm{~g} / \mathrm{L})$.

$$
\begin{aligned}
& E_{\mathrm{v}}=\frac{\gamma_{\mathrm{ss}}}{\gamma_{\max }} \times 100 \%, \\
& E_{\mathrm{e}}=\frac{\gamma_{\max }-\gamma_{\mathrm{ss}}}{\gamma_{\max }} \times 100 \% .
\end{aligned}
$$

2.3. Test Results and Analysis. Figure 4 shows the Dh distribution of different $M_{\mathrm{w}}$ with a polymer concentration of $0.5,1.0,1.5,2.0$, and $2.5 \mathrm{~g} / \mathrm{L}$. Table 1 shows the Dh equivalent 


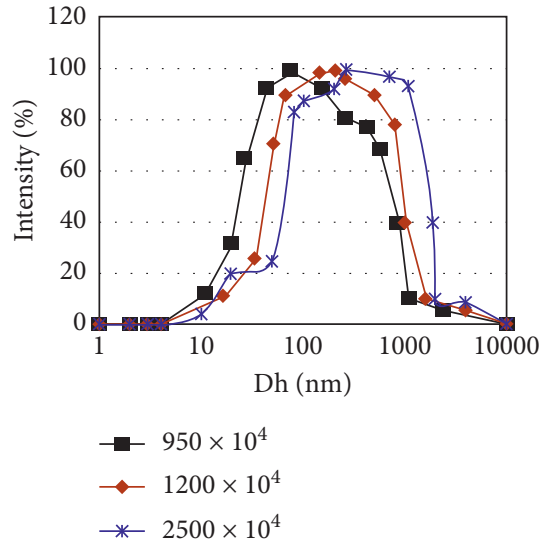

(a)

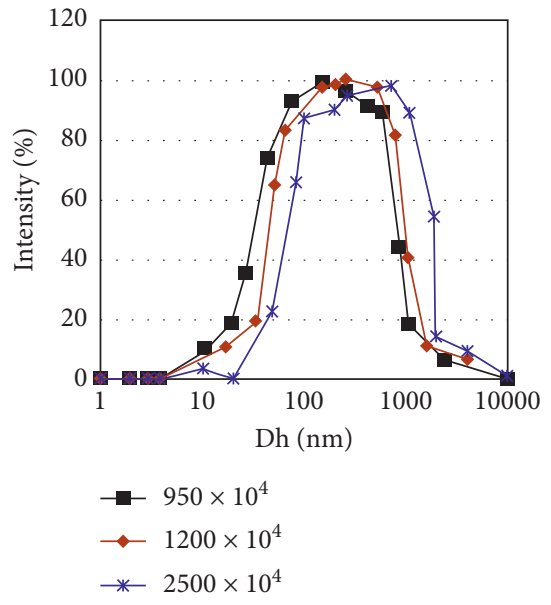

(d)

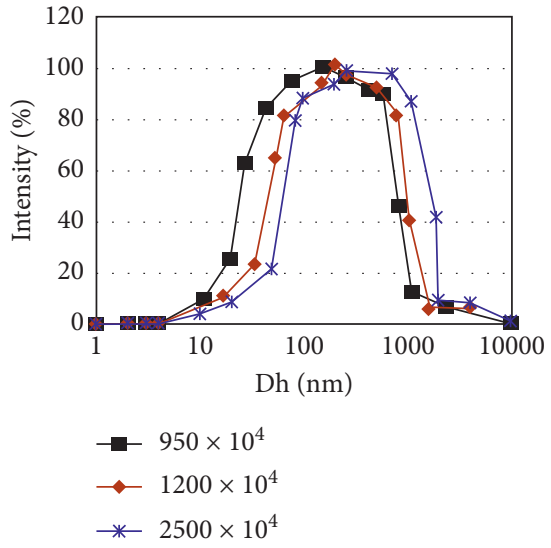

(b)

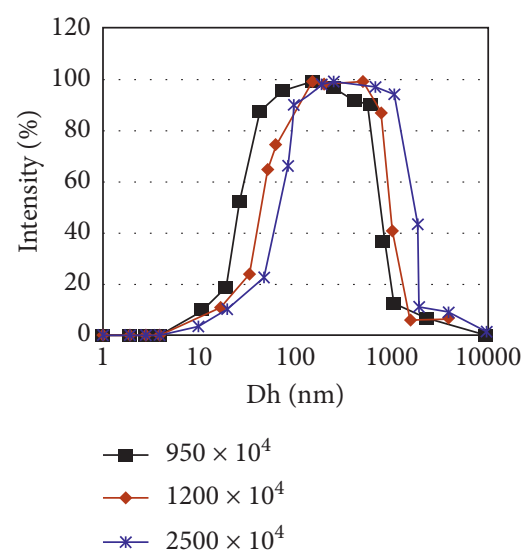

(c)

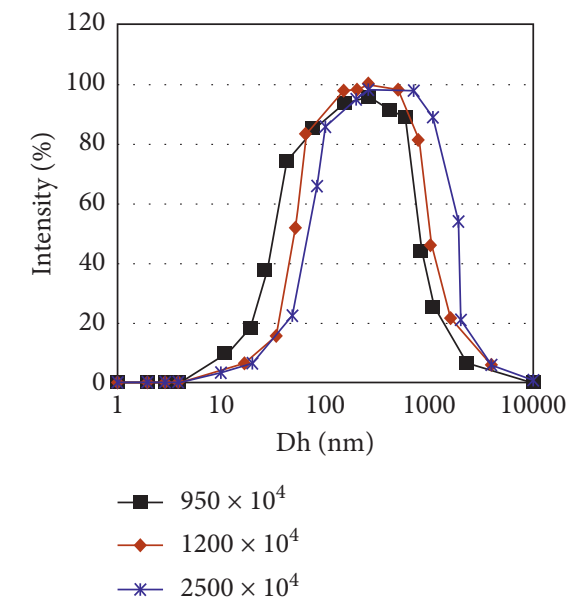

(e)

Figure 4: Distribution curve of Dh with different $\mathrm{Mw}$ and polymer concentrations. (a) Concentration, $0.5 \mathrm{~g} / \mathrm{L}$. (b) Concentration, $1.0 \mathrm{~g} / \mathrm{L}$. (c) Concentration, $1.5 \mathrm{~g} / \mathrm{L}$. (d) Concentration, $2.0 \mathrm{~g} / \mathrm{L}$. (e) Concentration, $2.5 \mathrm{~g} / \mathrm{L}$.

TAble 1: $E_{\mathrm{e}}$ and $E_{\mathrm{v}}$ with different Dh equivalent peaks.

\begin{tabular}{ccccc}
\hline$M_{\mathrm{w}}\left(\times 10^{4}\right)$ & $C_{\mathrm{P}}(\mathrm{g} / \mathrm{L})$ & $\mathrm{Dh}(\mathrm{nm})$ & $E_{\mathrm{e}}(\%)$ & $E_{\mathrm{v}}(\%)$ \\
\hline \multirow{4}{*}{950} & 0.5 & 126.3 & 4.12 & 95.88 \\
& 1 & 183.7 & 7.36 & 92.64 \\
& 1.5 & 264.3 & 12.11 & 87.89 \\
& 2 & 289.4 & 20.1 & 79.9 \\
& 2.5 & 303.2 & 24.4 & 75.6 \\
\hline \multirow{4}{*}{1200} & 0.5 & 138.2 & 14.96 & 85.04 \\
& 1 & 218.9 & 13.43 & 86.57 \\
& 1.5 & 282.5 & 18 & 82 \\
& 2 & 302.7 & 22.42 & 77.58 \\
& 2.5 & 319.7 & 35.02 & 64.98 \\
\hline \multirow{4}{*}{2500} & 0.5 & 159.7 & 26.23 & 73.77 \\
& 1 & 240.3 & 34.21 & 65.79 \\
& 1.5 & 301.4 & 34.32 & 65.68 \\
& 2 & 312.1 & 38.24 & 61.76 \\
& 2.5 & 327.8 & 82.7 & 17.3 \\
\hline
\end{tabular}

peak of different $M_{\mathrm{w}}$ with the polymer of different concentrations.

Figure 5 shows the result of the creep recovery test of the polymer solution under the same creep time condition, which includes the $M_{\mathrm{w}}$ of $950 \times 10^{4}, 1200 \times 10^{4}$, and $2500 \times 10^{4}$ with the $C_{\mathrm{p}}$ from 0.5 to $2.5 \mathrm{~g} / \mathrm{L}$.

Figure 6 and Table 1 show the proportion of the viscosity and elasticity parts with different $\mathrm{Dh}, M_{\mathrm{w}}$, and $C_{\mathrm{p}}$. It can be seen from the creep recovery test results that with the increase of the molecular coil dimension, deformation decreases gradually and the proportion of the elastic part of the solution increases gradually and even exceeds the viscous part. This is due to the increase of the polymer molecular coil dimension. The molecules in the system are more easy to wind together and the ability to resist the external force is strong, at the same time due to the increase of electrostatic repulsion within the molecular coil; so, it is not easy to be deformed.

From the Dh distribution curve of different $M_{\mathrm{w}}$ with same $C_{\mathrm{p}}$, we can see that, the higher the $M_{\mathrm{w}}$ of polymer is, the longer the molecular chain and the more complex the conformation is, and the size of Dh is larger. On the condition of the polymer solution with different $M_{\mathrm{w}}$ with $2.5 \mathrm{~g} /$ $\mathrm{L}$, when $\mathrm{Dh}$ is between $320.0 \mathrm{~nm}$ and $327.8 \mathrm{~nm}$, the ratio of the elastic part in the apparent viscosity exceeds the proportion of the viscous part, and the polymer solution 

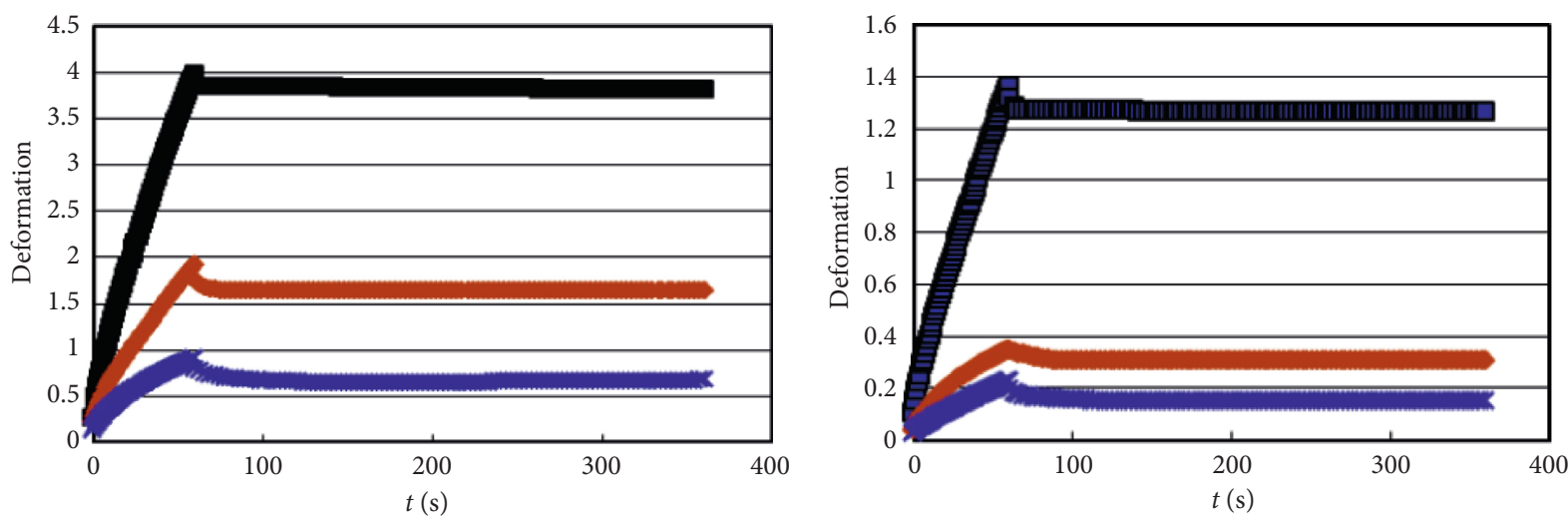

- $\mathrm{Dh}=126.3 \mathrm{~nm}$

- $\mathrm{Dh}=183.7 \mathrm{~nm}$

$\multimap-\mathrm{Dh}=138.2 \mathrm{~nm}$

$\multimap-\mathrm{Dh}=218.9 \mathrm{~nm}$

$\leftarrow \mathrm{Dh}=159.7 \mathrm{~nm}$

$\star \mathrm{Dh}=240.3 \mathrm{~nm}$

(a)

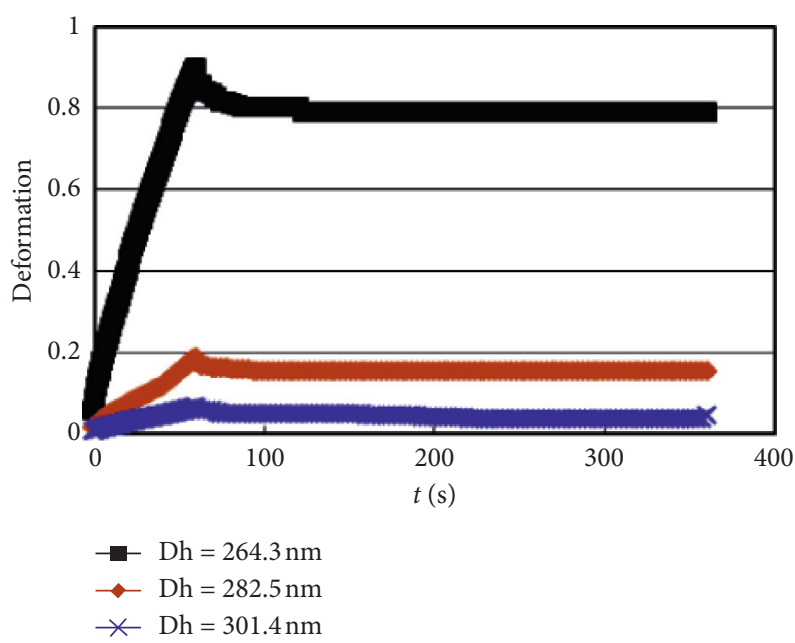

(c)

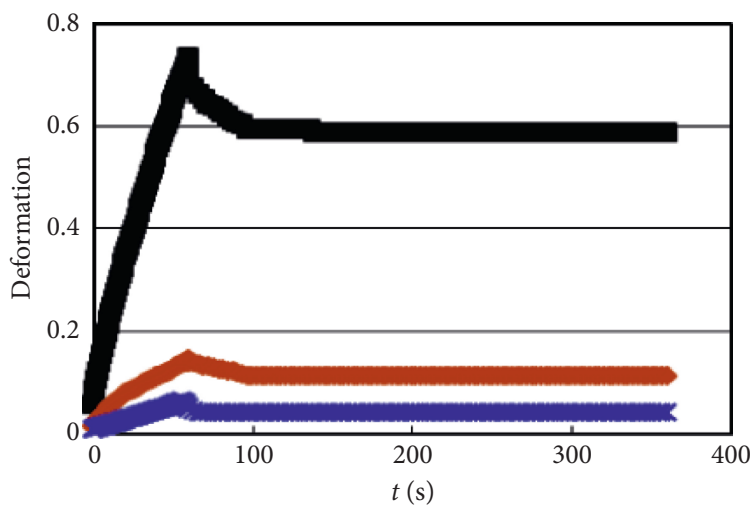

- $\mathrm{Dh}=289.4 \mathrm{~nm}$

$\multimap \mathrm{Dh}=302.7 \mathrm{~nm}$

$\star \mathrm{Dh}=312.1 \mathrm{~nm}$

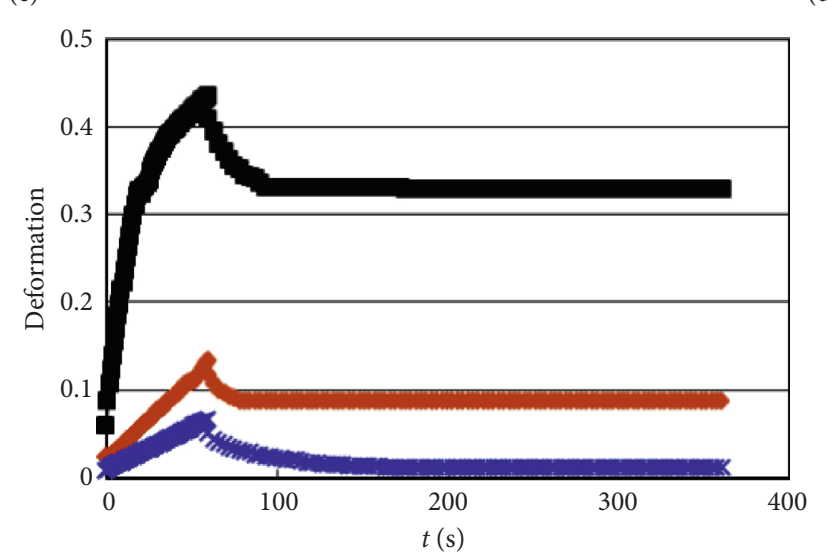

(d)

(b) 


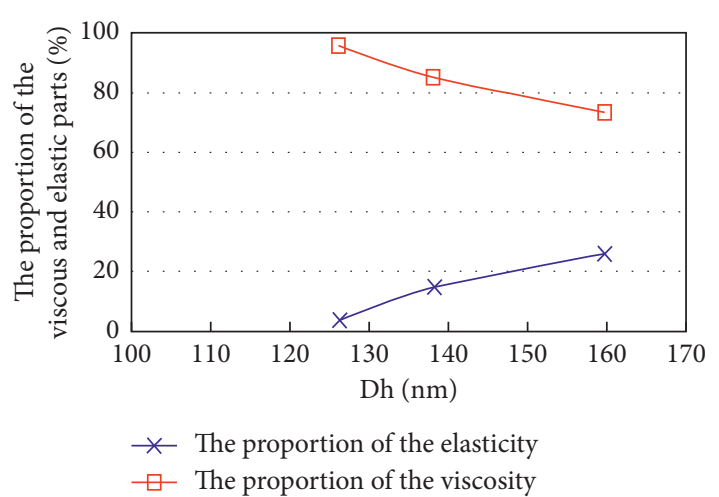

(a)

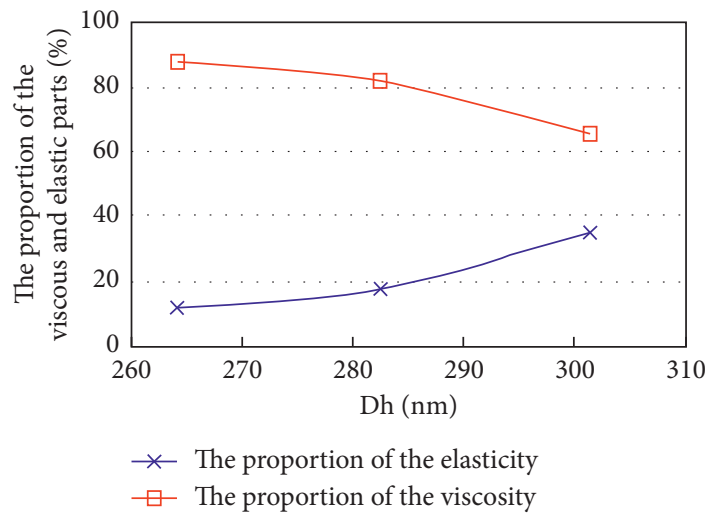

(c)

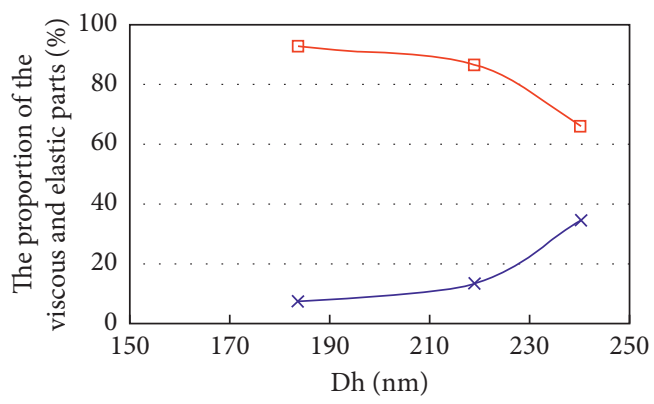

$*$ The proportion of the elasticity

$\square$ The proportion of the viscosity

(b)

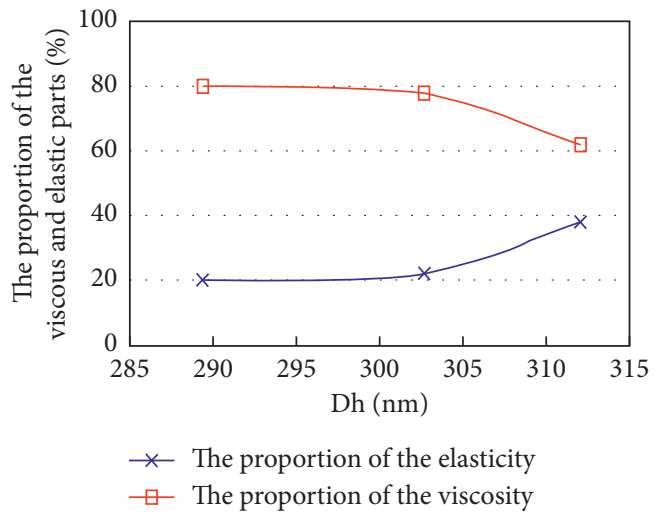

(d)

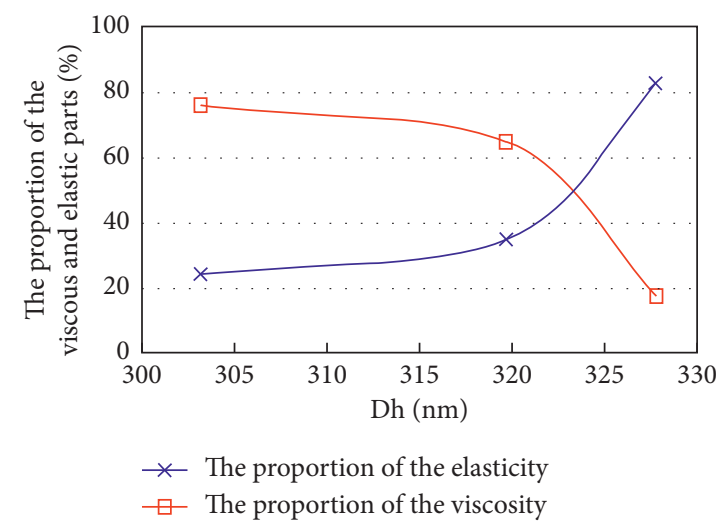

(e)

Figure 6: The proportion of the viscosity and elasticity parts of different Dh. (a) $0.5 \mathrm{~g} / \mathrm{L}$. (b) $1.0 \mathrm{~g} / \mathrm{L}$. (c) $1.5 \mathrm{~g} / \mathrm{L}$. (d) $2.0 \mathrm{~g} / \mathrm{L}$. (e) $2.5 \mathrm{~g} / \mathrm{L}$.

composition after these data can be used as a comparative study of elasticity for residual oil use.

\section{Oil Displacement Experiments and Analysis}

The effects of different elastic polymer solutions with different Dh on residual oil are observed, using the visible pore model.

3.1. Experimental Materials and Experimental Conditions. The experimental temperature is $45^{\circ} \mathrm{C}$, and the experimental oil is a type of simulated oil prepared from crude oil (viscosity value is $10.0 \mathrm{MPa} \cdot \mathrm{s}, 45^{\circ} \mathrm{C}$ ).
The $M_{\mathrm{w}}$ of polyacrylamide (HPAM) used in the experiments is $2500 \times 10^{4}$, and the concentration of the polymer solution is spate $0.5 \mathrm{~g} / \mathrm{L}, 1.5 \mathrm{~g} / \mathrm{L}$, and $2.5 \mathrm{~g} / \mathrm{L}$.

Salinity mineralization of water used in experiments is $6.778 \mathrm{~g} / \mathrm{L}$.

The model used in the visual experiment is a transparent glass homogeneous core etched according to the actual core pore structure. The model have two kinds: model 1 has a pore size of 105.0 microns and a throat size of 30.0 microns; the pore throat ratio of model 1 is 3.5 . Model 2 has a pore size of 210.0 microns and a throat size of 30.0 microns; the pore throat ratio of model 2 is 7.0 . The injection rate is $0.02 \mathrm{ml} / \mathrm{hr}$. 


\subsection{Experimental Procedure}

(1) The microscopic model injects oil

(2) The displacement speed of the simulated oil layer is constant speed water flooding, and displace the water until the oil is not seen at the exit

(3) Inject the viscoelastic polymer solution at a constant speed to drive the oil, record the dynamic image during the displacement process, and record the images before and after the flooding

(4) Calculate the oil displacement efficiency $\left(E_{\mathrm{R}}\right)$ under each displacement condition

(5) Clean the core and finish the experimental equipment

(6) Continue the experiment changing the concentration of the polymer solution and repeat the first five steps

\subsection{Experimental Results and Analysis}

3.3.1. Rheological Parameters of the Polymer Solution. The rheological curves of the polymer solution system are shown in Figure 7, the determined $M_{\mathrm{w}}$ of the polyacrylamide (HPAM) used in the experiments is $2500 \times 10^{4}$, and the concentrations of polymer solution $\left(\mathrm{C}_{\mathrm{p}}\right)$, respectively, are $0.5 \mathrm{~g} / \mathrm{L}, 1.5 \mathrm{~g} / \mathrm{L}$, and $2.5 \mathrm{~g} / \mathrm{L}$. The storage modulus $\left(\mathrm{G}^{\prime}\right)$ and dissipation modulus $\left(\mathrm{G}^{\prime \prime}\right)$ of polymer solutions are tested. The test results are shown in Figures 8 and 9. It can be ground from the viscous relationship curve, and the viscosity gradually increases by increasing the concentration of the polymer.

3.3.2. Analysis of Oil Displacement Experiment Results. The $E_{\mathrm{R}}$ results of oil displacement experiments for the polymer solution with different $\mathrm{Dh}$ under different porethroat ratio visual models are shown in Table 2 . The results of residual oil in the visual pore model are shown in Figures 10 and 11 .

In the visible pore model, the pore-throat ratio is 3.5 , the $E_{\mathrm{R}}$ of water flooding is $54.26 \%$, the $\mathrm{E}_{\mathrm{R}}$ of the polymer solution with $\mathrm{Dh}=159.7 \mathrm{~nm}$ is $75.28 \%$, and the increase of $E_{\mathrm{R}}$ of the polymer solution is $21.02 \%$ than that of water flooding. With the increase of $\mathrm{Dh}$ of $327.8 \mathrm{~nm}$, the final $E_{\mathrm{R}}$ of the experimental polymer solution is $97.82 \%$, and the increase of $E_{\mathrm{R}}$ of the polymer solution than that of water flooding is $43.56 \%$. However, in the model with a pore-throat ratio of 7.0 , the same polymer solution with the $\mathrm{Dh}=327.8 \mathrm{~nm}$, the increase of $E_{\mathrm{R}}$ of the polymer solution is only $10.44 \%$ higher than that of water flooding. The effect of the polymer solution with the same Dh is deteriorated, as the pore-throat ratio increases.

The experimental results show that, in the same porethroat ratio model, as the Dh of polymer solution increases,

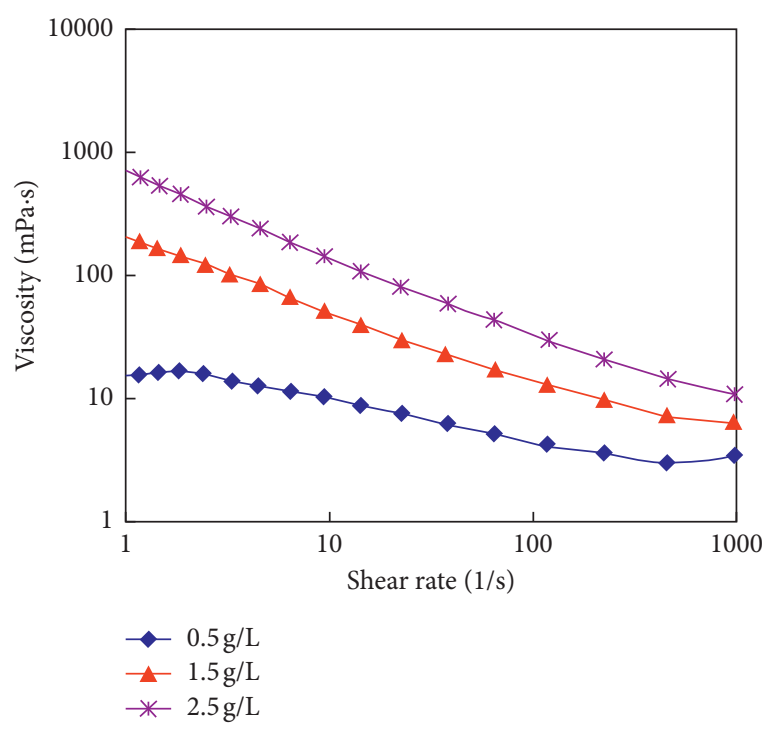

Figure 7: The curve of the polymer solution with different $C_{\mathrm{p}}$ $\left(M_{\mathrm{w}}=2500 \times 10^{4}\right)$.

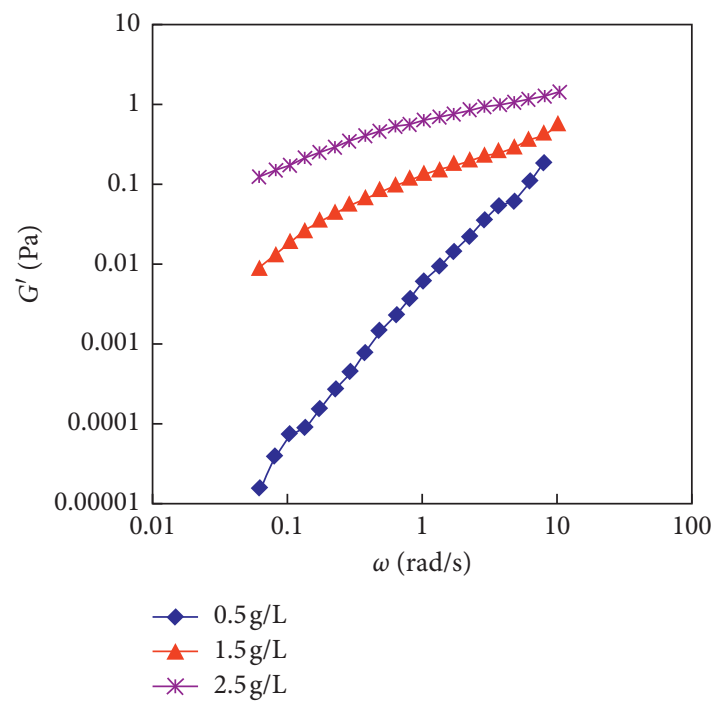

FIgURE 8: The storage modulus of the polymer solution with different $C_{\mathrm{p}}\left(M_{\mathrm{w}}=2500 \times 10^{4}\right)$.

the residual oil in the visual pore model gradually decreases. As the pore-throat ratio increases, the $E_{\mathrm{R}}$ of polymer solution with the same Dh gradually deteriorates, and a polymer solution with a larger $\mathrm{Dh}$ is needed. The residual oil displacement pictures show that under the same flow velocity conditions and the same pore throat conditions, the creep recovery conditions after the polymer macromolecules flow out of the throat are similar. The deformation of the modulus part restores the force acting on the external stress feedback, and the shear force on the Newtonian fluid in the pores gradually increases. 


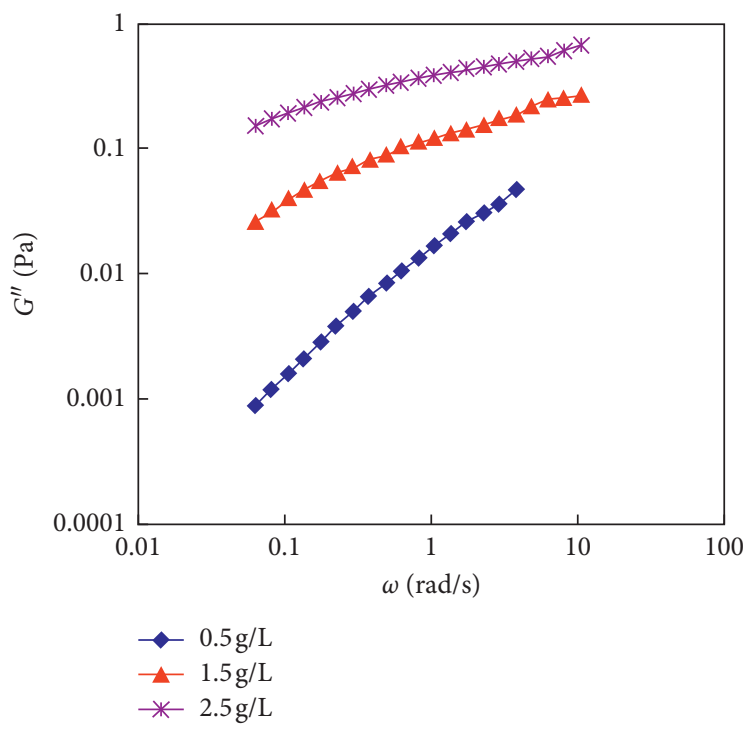

Figure 9: The energy consumption modulus of the polymer solution with different $C_{\mathrm{p}}\left(M_{\mathrm{w}}=2500 \times 10^{4}\right)$.

TABLe 2: Oil displacement efficiency of the polymer solution with different $\mathrm{Dh}\left(M_{\mathrm{w}}=2500 \times 10^{4}\right)$.

\begin{tabular}{lccccc}
\hline \multirow{2}{*}{ Pore-throat ratio } & $C_{\mathrm{p}}(\mathrm{g} / \mathrm{L})$ & 0.0 & 0.5 & 1.5 & 2.5 \\
& $\mathrm{Dh}(\mathrm{nm})$ & - & 159.7 & 301.4 & 327.8 \\
\hline \multirow{2}{*}{3.5} & $E_{\mathrm{R}}(\%)$ & 54.26 & 75.28 & 88.15 \\
& $E_{\mathrm{R}}$ improvement $(\%)$ & - & 21.02 & 33.89 & 43.82 \\
\multirow{2}{*}{7.0} & $E_{\mathrm{R}}(\%)$ & 50.41 & 52.93 & 54.31 & 60.85 \\
& $E_{\mathrm{R}}$ improvement $(\%)$ & - & 2.52 & 3.9 & 10.44 \\
\hline
\end{tabular}

$E_{\mathrm{R}}$ improvement $=E_{\mathrm{R}}$ (polymer flooding) $-E_{\mathrm{R}}$ (water flooding).

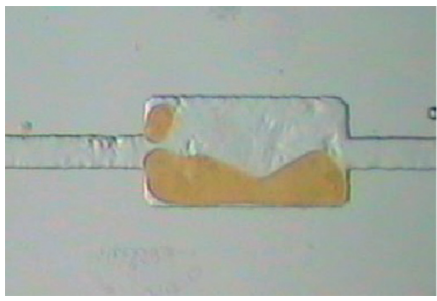

(a)

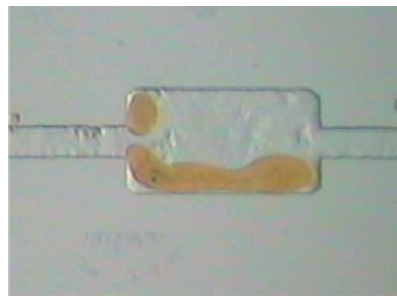

(b)

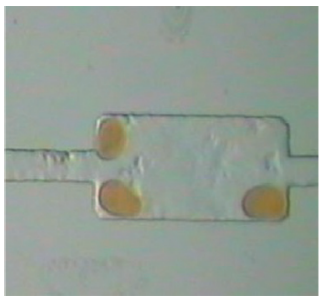

(c)

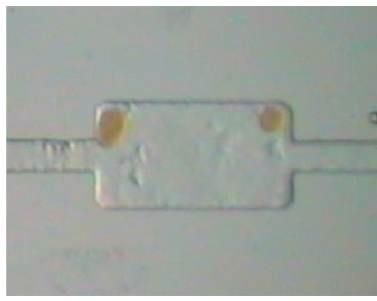

(d)

FIGURE 10: Distribution of residual oil after displacement with different Dh (pore-throat ratio 3.5). (a) Water flooding. (b) Dh $=159.7 \mathrm{~nm}$. (c) $\mathrm{Dh}=301.4 \mathrm{~nm}$. (d) $\mathrm{Dh}=327.8 \mathrm{~nm}$.

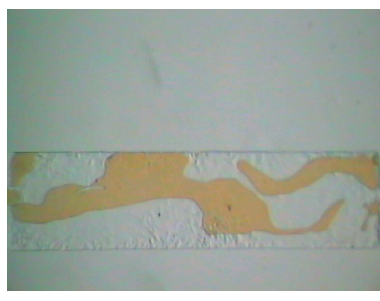

(a)

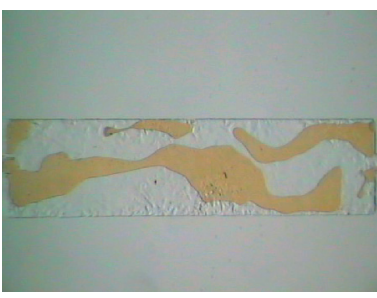

(b)

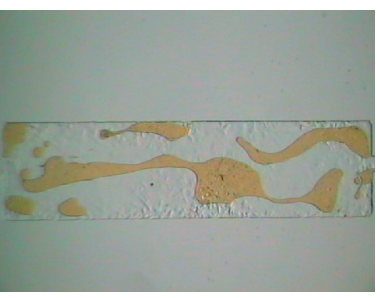

(c)

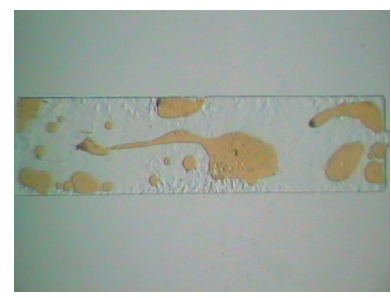

(d)

FIGURE 11: Distribution of residual oil after displacement with different Dh (pore-throat ratio 7.0). (a) Water flooding. (b) Dh $=159.7 \mathrm{~nm}$. (c) $\mathrm{Dh}=301.4 \mathrm{~nm}$. (d) $\mathrm{Dh}=327.8 \mathrm{~nm}$. 


\section{Conclusions}

The following conclusions were made on the basis of the experimental work performed:

(1) The higher the $M_{\mathrm{w}}$ of the polymer, the larger the size of the molecular coil dimension.

(2) The elasticity characteristics of polymer solution are sensitive to the molecular coil dimension. As Dh of the polymer molecules becomes larger, the contribution of the elastic portion to the viscosity of the polymer solution increases.

(3) In the same pore-throat ratio model, as the Dh of polymer solution increases, the residual oil in the visual pore model gradually decreases. As the porethroat ratio increases, the $E_{\mathrm{R}}$ of polymer solution with the same Dh gradually deteriorates, and a polymer solution with a larger $\mathrm{Dh}$ is needed.

(4) Under the same flow velocity conditions and the same pore throat conditions, the deformation of the modulus part restores the force acting on the external stress feedback, and the shear force on the Newtonian fluid in the pores gradually increases.

\section{Data Availability}

Both the molecular coil dimension data and creep recovery data of the polymer solution used to support the findings of this study are included within this article. The oil displacement experiment data of the visible pore model used to support the findings of this study are currently restricted by the important national science and technology specific projects in order to protect the privacy of the related patients. However, all these data are available from Wenguo Ma (Email: mawenguo110@163.com) for researchers who meet the criteria for access to confidential data.

\section{Conflicts of Interest}

The authors declare that they have no conflicts of interest.

\section{Acknowledgments}

This research was financially supported by the Youth Science Foundation of Northeast Petroleum University (project number, 2013NQ122), National Science and Technology Major Projects (Grant nos. 2016ZX05010-002-004 and 2016ZX05058-00010), and project 202010220033 supported by National Training Program of Innovation and Entrepreneurship for Undergraduates.

\section{References}

[1] Y. Du and L. Guan, "Field-scale polymer flooding: lessons learnt and experiences gained during past 40 years," in Proceedings of the SPE International Petroleum Conference, pp. 383-388, Puebla, Mexico, November 2004.

[2] Y. Wang, Y. Pang, Z. Shao et al., "The polymer flooding technique applied at high water cut stage in daqing oilfield," in
Proceedings of the North Africa Technical Conference \& Exhibition, Cairo, Egypt, April 2013.

[3] J. Wang and H. Liu, "A novel model and sensitivity analysis for viscoelastic polymer flooding in offshore oilfield," Journal of Industrial and Engineering Chemistry, vol. 20, no. 2, pp. 656-667, 2014.

[4] B. Y. Jamaloei and R. Kharrat, "Analysis of microscopic displacement mechanisms of dilute surfactant flooding in oilwet and water-wet porous media," Transport in Porous Media, vol. 81, no. 1, pp. 1-19, 2010.

[5] M. Zallaghi, R. Kharrat, and A. Hashemi, "Improving the microscopic sweep efficiency of water flooding using silica nanoparticles," Journal of Petroleum Exploration and Production Technology, vol. 8, no. 1, pp. 259-269, 2018.

[6] H. Zhong, Q. Zang, H. Yin, and H. Xia, "Experimental study on medium viscosity oil displacement using viscoelastic polymer," Geofluids, vol. 2018, Article ID 4321380, 11 pages, 2018.

[7] Y. Liu, J. Fan, L. Liu, S. Yang, and Z. Rui, "Numerical simulation of residual oil flooded by polymer solution in microchannels," Geofluids, vol. 2018, Article ID 8947839, 10 pages, 2018.

[8] L. Liu, S. Yang, and J. Fan, "Stress calculation of polymer displacing residual oil in micro pores," International Journal of Performability Engineering, vol. 13, no. 2, 2017.

[9] L. Wenli, M. Desheng, N. Xiaobin et al., "Study on matching relation between polymer molecular size and pore size for conglomerate reservoir," in Proceedings of the International Petroleum Technology Conference Challenging Technology and Economic Limits to Meet the Global Energy Demand (IPTC'13), pp. 1778-1786, Beijing, China, March 2013.

[10] W. G. Ma, P. Wang, and Y. Wang, "The study of daqing oilfield class II reservoirs pore throat ratio using the conventional pressure mercury method," Applied Mechanics and Materials, vol. 423-426, pp. 622-625, 2013.

[11] W-g Ma and A-x Liu, "The study of rocks, the pore structure parameters in by CT scanning technology," Sino-Global Energy, vol. 16, pp. 54-56, 2011.

[12] E. C. M. Vermolen, M. J. T. van Haasterecht, and S. K. Masalmeh, "A systematic study of the polymer viscoelastic effect on residual oil saturation by core flooding," in Proceedings of the SPE EOR Conference at Oil and Gas West Asia, Muscat, Oman, April 2014.

[13] Y. Zhou, D. Yin, W. Chen, B. Liu, and X. Zhang, "A comprehensive review of emulsion and its field application for enhanced oil recovery," Energy Science \& Engineering, vol. 7, pp. 1046-1058, 2019.

[14] Y. Zhou, D. Yin, R. Cao, and C. Zhang, "The mechanism for pore-throat scale emulsion displacing residual oil after water flooding," Journal of Petroleum Science and Engineering, vol. 163, pp. 519-525, 2018. 